\title{
Synthetic method of polyethylene- poly(methylmethacrylate) (PE-PMMA) polymer hybrid via reversible addition-fragmentation chain transfer (RAFT) polymerization with functionalized polyethylene
}

\author{
Nobuo Kawahara ( $₫)$, Shin-ichi Kojoh, Shingo Matsuo, Hideyuki Kaneko, \\ Tomoaki Matsugi, Junji Saito, Norio Kashiwa \\ R\&D Center, Mitsui Chemicals, Inc., 580-32 Nagaura, Sodegaura-City, Chiba 299-0265, \\ JAPAN \\ E-mail: Nobuo.Kawahara@mitsui-chem.co.jp; Fax: +81-438-64-2377
}

Received: 18 April 2006 / Revised version: 20 June 2006 / Accepted: 29 June 2006

Published online: 27 July 2006 - (C) Springer-Verlag 2006

\section{Summary}

Polyethylene-poly(methylmethacrylate) (PE-PMMA) polymer hybrid was synthesized via RAFT polymerization of MMA with PE chain transfer agent (PE-CTA) for the first time. The structure of PE-CTA produced by sequential functionalization of terminally hydroxylated PE was confirmed by ${ }^{1} \mathrm{H}$ NMR and FT-IR analyses. The results of GPC after MMA polymerization revealed that the molecular weight $\left(M_{\mathrm{w}}\right)$ of the resulting polymers increased compared with the one of the PE-CTA. ${ }^{1} \mathrm{H}$ NMR analysis of resulting polymers confirmed that the amounts of PMMA segments were in a range of 7.8 and $23 \mathrm{wt} \%$. TEM images indicated the nanometer level microphaseseparation morphology between the PE segment and PMMA segment.

\section{Introduction}

Polyolefins (POs) represented by polyethylene (PE) and polypropylene have been indispensable materials in our dairy lives since the discovery of Zieglar-Natta catalysts. Those are produced over 80 million tons per year in the worldwide now a day [1]. Recent advances in polyolefin chemistry have led to the creation of polymer hybrid linking between POs and polar polymer segments by combination between functionalized POs and several processes such as radical, anionic, cationic polymerizations and post polymerization reactions, bringing the ordinary POs some improved and unique properties to broaden the applications of POs to highly profitable fields [2-5].

Allowing for the production of polymer hybrid based on POs, in the early stage, irradiated PO was used as an initiator for radical polymerization [6, 7]. That method, however, was difficult to control the graft density and the side chain length of polar polymer segments. In recent years, several studies have been reported by using control radical polymerization (CRP) methods [8-14]. CRP would be attractive tools because of the controllability of polymerization, and they would be expected as versatile 
methods to synthesis of well-defined polymer hybrids. However, the atom transfer radical polymerization (ATRP) [8-12], which is a transition metal mediated radical polymerization, is adopted in many cases of them, and removal step of the catalyst ash is needed for purification of resulting polymer in case of ATRP. Moreover, other CRP methods have hardly been studied to produce polymer hybrid based on PO.

In previous studies of RAFT polymerization, which is a metal free CRP method [1721], several polymer hybrids based on polystyrene, cellulose, FEP film and silica surface, have already been reported [13-16]. Our motivation in this study was to apply the RAFT polymerization method to synthesize polymer hybrids based on PO. At first, we synthesized the PE chain transfer agent (PE-CTA) possessing the dithiobenzoate group obtained by sequential functionalization of terminally hydroxylated PE. Then, PE-PMMA polymer hybrids were produced via RAFT polymerization.

\section{Experimental Section}

\section{Materials}

Dimethylsilylene(2,7-tert-butyl-fluorenyl)(2-methyl-benz[e]indenyl)zirconium dichloride was prepared according with previous paper [22]. Methylaluminoxane (MAO) purchased from Albemarle Co. was dried under vacuum and diluted in toluene. Allyl alcohol was purchased from Tokyo Kasei Kogyo Co., Ltd. and purified by distillation. Triisobutylaluminum (TIBAL) was purchased from Tosoh Finechem Co. and used as received. Toluene purchased from Wako Pure Chemical Industries, Ltd. was dried over sodium metal and distilled before use. Tetrahydrofurane (THF) purchased from Wako Pure Chemical Industries, Ltd. was dried over sodium/potassium alloy and distilled before use. Ethylene monomer (Mitsui Chemicals) was used without any further purification. 2-Chloro-2-phenylacetyl chloride was purchased from Wako Pure Chemical Industries, Ltd. and used as received. Triethylamine and carbon disulfide purchased from Wako Pure Chemical Industries, Ltd. were dried over molecular sieves (4A) before use. Phenyl magnesium chloride THF solution was purchased from Kanto Kagaku, Ltd. and used as received. Methylmethacrylate (MMA) was purchased from Wako Pure Chemical Industries, Ltd. and purified by distillation. Organometallic compounds were treated under the nitrogen atmosphere.

\section{Analysis}

1H NMR spectra were recorded on a JEOL JNM GSX400 spectrometer (400 MHz) with 1,1,2,2-tetrachloroethane-d4 or o-dichlorobenzene-d4 as solvents at $120^{\circ} \mathrm{C}$. The molecular weights $(M \mathrm{w}$ and $M \mathrm{n})$ of the polymers were determined at $145{ }^{\circ} \mathrm{C}$ with Waters Alliance GPC2000 equipped with four TSKgel columns (two TSKgel GMH6HT columns and two TSKgel GMH6-HTL columns) calibrated with PE. o-Dichlorobenzene was used as a solvent at a flow rate of $1.0 \mathrm{~mL} / \mathrm{min}$.. IR spectra were recorded on a JEOL FT-IR 410 spectrometer. TEM Analysis was carried out with ultrathin (ca. $100 \mathrm{~nm}$ ) sections of the polymer were cut on a Reica Ultracut microtome equipped with a diamond knife at a low temperature and then were stained with $\mathrm{RuO}_{4}$. TEM observations were made with a Hitachi H-7000 transmission electron microscope at an acceleration voltage of $75 \mathrm{kV}$. 


\section{Preparation of terminally Hydroxylated PE (PE-OH)}

Polymerization was carried out in $2 \mathrm{~L}$ of glass flasks equipped with mechanical stirrer, thermocouples and monomer inlet tube. Into the reactor, $1700 \mathrm{~mL}$ of toluene was introduced. After heating the solvent to $45^{\circ} \mathrm{C}$, triethylaluminum $(96 \mathrm{mmol})$ and allyl alcohol $(80 \mathrm{mmol})$ was added. Then, dimethylsilylene(2,7-tert-butyl-fluorenyl)(2methyl-benz[e]indenyl)zirconium dichloride $(0.05 \mathrm{mmol})$ activated by MAO in toluene solution (3.5 mmol as $\mathrm{Al}$ atom) was added into the reactor. The polymerization was started by introduction of ethylene gas. Polymerization temperature was kept at $50{ }^{\circ} \mathrm{C}$ under the constant ethylene feed, $10 \mathrm{NL} / \mathrm{h}$. After 3 hour, $20 \mathrm{~mL}$ of isobutanol was added to the reactor in order to terminate the polymerization. The reaction mixture was poured in $3 \mathrm{~L}$ of methanol. Resulting polymer was obtained by filtration and washed with methanol, then dried under the reduced pressure at $80{ }^{\circ} \mathrm{C}$ for 10 hour. $25.6 \mathrm{~g}$ of polymer was obtained. Molecular weights were as follows; $M_{\mathrm{w}}=36,600, M_{\mathrm{n}}=13,600, M_{\mathrm{w}} / M_{\mathrm{n}}=2.69$. The content of hydroxyl group in polymer was $0.16 \mathrm{~mol} \%$ (The estimated hydroxyl group content is 0.8 unit $[-\mathrm{OH}]$ per polymer chain).

\section{Preparation of Polyethylene-chloro(phenyl)acetylate (PE-CPA)}

PE-OH (30.95 g; $1.75 \mathrm{mmol}[\mathrm{OH}])$ was dissolved in toluene $(250 \mathrm{~mL})$ at $110^{\circ} \mathrm{C}$, and then it was cooled to $80{ }^{\circ} \mathrm{C}$. Triethylamine $(11 \mathrm{~mL}, 80 \mathrm{mmol})$ and 2-Chloro-2phenylacetyl chloride $(4.5 \mathrm{~mL}, 27 \mathrm{mmol})$ were added to the solution at that temperature. The reaction mixture was stirred at $80{ }^{\circ} \mathrm{C}$ for 4 hour. It was poured into $1 \mathrm{~L}$ of acetone. Obtained polymer was washed with methanol $(1 \mathrm{~L})$ and acetone $(1 \mathrm{~L})$, then, it was dried under vacuum at $50{ }^{\circ} \mathrm{C}$ for 10 hour. $29.65 \mathrm{~g}$ of polymer (PE-CPA) was obtained.

${ }^{1} \mathrm{H}$ NMR $\left(\mathrm{C}_{2} \mathrm{D}_{2} \mathrm{Cl}_{4}\right), \delta 0.85-1.80\left(-\mathrm{CH}_{2}-\right.$ or $\mathrm{CH}_{3}$ of PE), 3.80-4.20 (m, $\left.2 \mathrm{H},-\mathrm{CH}_{2}-\mathrm{O}-\right)$, $5.31(\mathrm{~s}, 1 \mathrm{H},-\mathrm{CH}(\mathrm{Ph}) \mathrm{Cl}), 7.25-7.65(\mathrm{~m}, 5 \mathrm{H}, \mathrm{Ar})$.

FTIR, $(\mathrm{KBr}): 1760(\mathrm{C}=\mathrm{O}), 1155 \mathrm{~cm}^{-1}(\mathrm{C}-\mathrm{O}-\mathrm{C})$.

\section{Preparation of Polyethylene-carbonylphenylmethyl dithiobenzoate (PE-CPDB)}

Phenyl magnesium chloride in THF (2M; $10 \mathrm{mmol})$ was transferred in a dried Schlenk flask. THF $(25 \mathrm{~mL})$ and carbon disulfide $(41.6 \mathrm{mmol})$ was added to dropwise to the flask over 10 minute, and the solution temperature was then raised to $40{ }^{\circ} \mathrm{C}$, forming a brown solution. The solution was transferred to another Schlenk flask containing PECPA $(15.0 \mathrm{~g})$ and THF $(120 \mathrm{~mL})$. The reaction mixture was stirred at $60{ }^{\circ} \mathrm{C}$ for 26 hour. It was poured into $1 \mathrm{~L}$ of acetone. Obtained polymer was washed with methanol $(1 \mathrm{~L})$ and acetone $(1 \mathrm{~L})$, then, it was dried under vacuum at $50{ }^{\circ} \mathrm{C}$ for 10 hour. $15.1 \mathrm{~g}$ of polymer (PE-CPDB) was obtained. It was used as PE-CTA.

${ }^{1} \mathrm{H}$ NMR $\left(\mathrm{C}_{2} \mathrm{D}_{2} \mathrm{Cl}_{4}\right), \delta 0.85-1.80\left(-\mathrm{CH}_{2}-\right.$ or $\mathrm{CH}_{3}$ of PE), 3.80-4.20 (m, $\left.-\mathrm{CH}_{2}-\mathrm{O}-\right), 5.30$ $(\mathrm{s},-\mathrm{CH}(\mathrm{Ph}) \mathrm{Cl}), 7.20-7.70(\mathrm{~m}, 10 \mathrm{H}, \mathrm{Ar}), 8.12(\mathrm{~d},-\mathrm{SC}(\mathrm{Ar}-\mathrm{H})(=\mathrm{S}))$.

FTIR, $(\mathrm{KBr}): 1760(\mathrm{C}=\mathrm{O}), 1155 \mathrm{~cm}^{-1}(\mathrm{C}-\mathrm{O}-\mathrm{C})$.

\section{Polymerization of MMA using PE-CPDB}

A typical polymerization process is as follows: after PE-CPDB (3.14 g) was placed in a $100 \mathrm{~mL}$ Schlenk flask equipped with a stirring bar, toluene $(15 \mathrm{~mL})$, MMA (10.7 $\mathrm{mL} ; 100 \mathrm{mmol})$ and a solution of AIBN (3.0 mg, $0.02 \mathrm{mmol})$ in toluene was added 
and the mixture was heated at $60{ }^{\circ} \mathrm{C}$ for 24 hour. After cooling, the reaction mixture was poured into $400 \mathrm{ml}$ of methanol and the white solid was collected by filtration. The obtained polymers were purified with boiling THF by Soxhlet extractor for 16 hour, and dried at $50{ }^{\circ} \mathrm{C}$ in vacuum for 20 hour.

\section{Results and discussion}

Preparation of PE-CTA

The synthesis of PE-CTA involved three steps (figure 1).
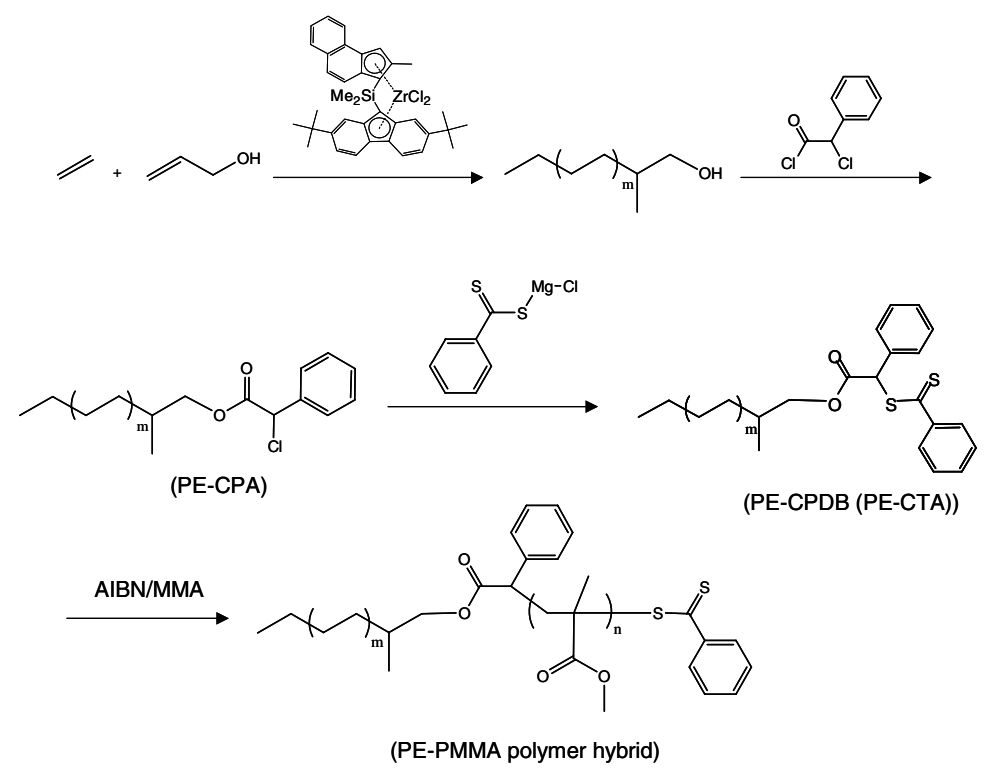

Figure 1. Synthetic route for PE-PMMA polymer hybrid via RAFT polymerization method

In the first step, PE-OH, which possessed primary alcohol at its chain end, was successfully obtained through the copolymerization of ethylene with aluminumprotected allyl alcohol with our proprietary metallocene catalyst system [22]. In the second step, the terminally hydroxyl group of PE was reacted with 2chlorophenylacetylchloride to produce PE-CPA. The reaction was performed under a solution condition at $80{ }^{\circ} \mathrm{C}$ through the addition of excess 2chlorophenylacetylchloride and triethylamine to yield sufficient reactivity of the terminal hydroxyl group enclosed by crystalline PE. In the third step, the PE-CPA was reacted with dithiocarbonyl compound to produce the PE-CPDB, which could be used as a chain transfer reagent (PE-CTA) for RAFT polymerization. The reaction was carried out below $80{ }^{\circ} \mathrm{C}$ to prevent the decomposition of the resulting compound.

Figure 2 shows the ${ }^{1} \mathrm{H}$ NMR spectra of PE-OH, PE-CPA and PE-CPDB. The multiple peaks of 3.2-3.4 ppm are assigned to methylene $\left(-\mathrm{CH}_{2}-\mathrm{OH}\right)$ at the terminal. From ${ }^{1} \mathrm{H}$ NMR analysis, $80 \%$ of chain end of the polyethylene was hydroxyl group. For PECPA, the multiple peaks of 3.8-4.2 ppm correspond to methylene (- $\left.\mathrm{CH}_{2}-\mathrm{O}-\right)$, and the single peak of $5.3 \mathrm{ppm}$ corresponds to methine $(-\mathrm{CH}(\mathrm{Ph}) \mathrm{Cl})$. The multiple peaks of 
6.9-7.5 ppm correspond to phenyl group; no peaks of methylene $\left(-\mathrm{CH}_{2}-\mathrm{OH}\right)$ are evident, and this indicates the presence of PE-CPA and the absence of unreacted hydroxyl group. For PE-CPDB, almost of all peaks are similar as PE-CPA except the multi peaks around $8.1 \mathrm{ppm}$. These would be assigned to two protons of phenyl group nearby dithiocarbonyl group.

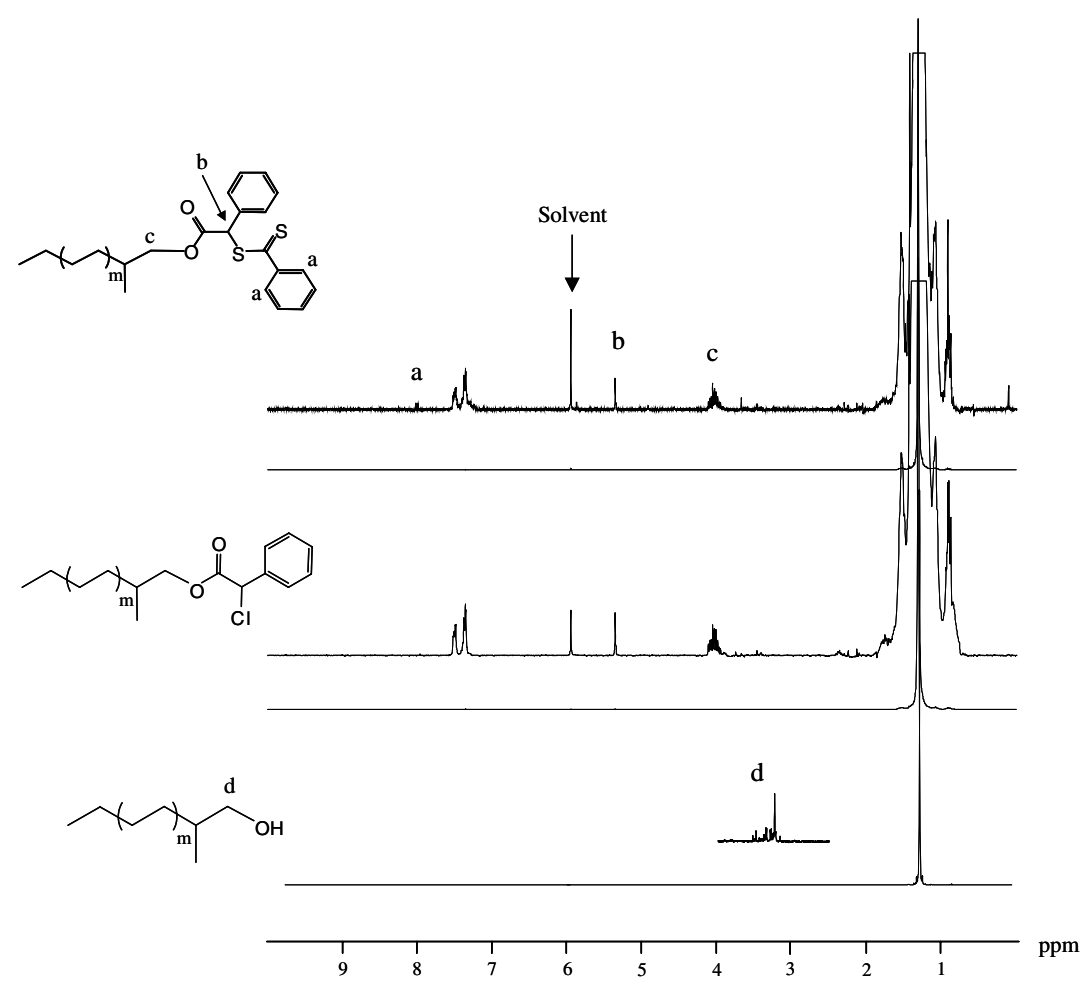

Figure 2. ${ }^{1} \mathrm{H}$ NMR spectra of PE-OH, PE-CPA and PE-CPDB

In FT-IR analyses of PE-CPA and PE-CPDB, the signals at 1760 and $1155 \mathrm{~cm}^{-1}$ were observed, assigned to carbonyl $(\mathrm{C}=\mathrm{O})$ and ether $(\mathrm{C}-\mathrm{O}-\mathrm{C})$ groups, respectively, indicating the ester bond was in both polymers. From those results of analyses, it would be indicated that PE chain transfer agent (PE-CTA) possessing the dithiobenzoate group was synthesized by sequential functionalization of terminally hydroxylated PE.

\section{RAFT polymerization of MMA initiated by AIBN}

We applied the RAFT polymerization method to create a polymer hybrid based on PO. The polymerization of MMA with PE-CTA was performed by using AIBN as an initiator at $60{ }^{\circ} \mathrm{C}$ in toluene under a slurry condition. The weight ratios of the PE-CTA to the AIBN were set at $1000 / 1$ or $2000 / 1$, and the weight ratio of total monomer to the PE-CTA was set at 10/3. The polymerization was stopped by cooling of reactor with ice bath. The polymerization mixture was poured into methanol, collecting all polymers. To remove homo-PMMA, the obtained polymers were purified with 
Soxhlet extractor with boiling THF. In both samples, there were observed some amounts of homo-PMMA (ca. 1-2g of homo-PMMA were collected by Soxhlet extraction with boiling THF). Table 1 summarizes the results of polymerization for two polymerization conditions. In both cases, the amounts of purified polymers after the Soxhlet extraction increased compared with the one of the PE-CTA as starting material.

Table 1. Summary of MMA polymerization ${ }^{\text {a) }}$

\begin{tabular}{|c|c|c|c|c|c|c|c|c|}
\hline \multirow[t]{2}{*}{ Run \# } & \multirow{2}{*}{$\begin{array}{c}\text { PE- } \\
\text { CTA } \\
(\mathrm{g})\end{array}$} & \multirow{2}{*}{$\begin{array}{c}\text { MMA } \\
\text { (g) }\end{array}$} & \multirow{2}{*}{$\begin{array}{l}\text { AIBN } \\
(\mathrm{mg})\end{array}$} & \multirow{2}{*}{$\begin{array}{l}\text { Yield }^{\text {b) }} \\
(\mathrm{g})\end{array}$} & \multirow{2}{*}{$\begin{array}{c}\text { PMMA } \\
\text { Contents } \\
\text { (wt } \% \text { in } \\
\text { polymer) }\end{array}$} & \multicolumn{3}{|c|}{$\mathrm{GPC}^{\mathrm{d})}$} \\
\hline & & & & & & $M_{\mathrm{w}}$ & $M_{\mathrm{n}}$ & $M_{\mathrm{w}} / M_{\mathrm{n}}$ \\
\hline P-1 & 3.14 & 5.0 & 3.0 & 3.41 & 7.8 & 38,500 & 16,100 & 2.39 \\
\hline P-2 & 3.31 & 10.0 & 1.5 & 4.21 & 23.0 & 40,000 & 17,100 & 2.34 \\
\hline PE-OH & - & - & - & - & 0 & 36,600 & 12,900 & 2.84 \\
\hline
\end{tabular}

a) All polymerization were carried out at $60{ }^{\circ} \mathrm{C}$ for 24 hour in toluene. The total volume of each polymerization was $30 \mathrm{~mL}$. b) after purification of obtained polymer samples by Soxhlet extractor with boiling THF. c) estimated by ${ }^{1} \mathrm{H}$ NMR measurement. d) GPC data (PE standard).

Gel permeation chromatography (GPC) measurements revealed that the molecular weight $\left(\mathrm{M}_{\mathrm{w}}\right)$ of the purified polymers increased from 36,600 by PE-CTA, to 38,500 and 40,000 , respectively (shown in figure 3). The $M_{w} / M_{n}$ ratios of the purified polymers were between 2.3 and 2.4, gotten smaller than one of the PP-OH, 2.84. These results would show the formation of PE-PMMA polymer hybrid via RAFT polymerization.

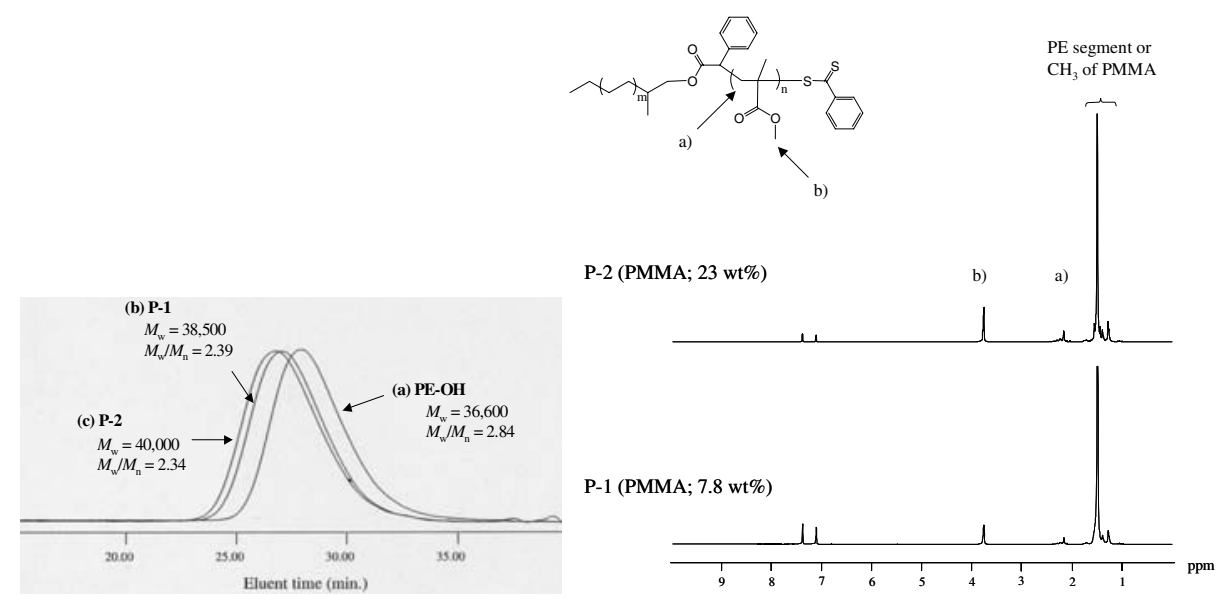

Figure 3. GPC traces of (a) PE-OH and purified polymers with PMMA contents of

Figure 4. ${ }^{1} \mathrm{H}$ NMR spectra of purified polymer (b) $7.8 \mathrm{wt} \%(\mathrm{P}-1)$ and (c) $23 \mathrm{wt} \%(\mathrm{P}-2)$ 
The purified polymers were analyzed at $120{ }^{\circ} \mathrm{C}$ with ${ }^{1} \mathrm{H}$ NMR with odichlorobenzene- $\mathrm{d}_{4}$ as a solvent. The PMMA contents in the purified polymers were calculated at the ratio of two integrated intensities between $3.6 \mathrm{ppm}$ (assigned to the methyl protons of the PMMA segment) and $1.3 \mathrm{ppm}$ (assigned to the methylene protons of PE). From the ${ }^{1} \mathrm{H}$ NMR spectra shown in figure 4 , the purified polymers contained 7.8 and $23 \mathrm{wt} \%$ of PMMA segment, respectively.

\section{Microstructure of resulting polymers}

Figure 5 shows TEM images of PE-CTA and purified polymers of PE-PMMA. In case of PE-CTA (before MMA polymerization), the lamella originated by PE was observed clearly. In purified polymers (after MMA polymerization), however, the nanostructures of them would change compared with PE-CTA, as like that the lamellar was come loose according to PMMA contents. In this study, MMA polymerization with PE-CTA was performed under a slurry condition. Therefore, it would be suggested from TEM images that PMMA chain was grown on the surface of PE-CTA particle and in parts of amorphous of PE-CTA.

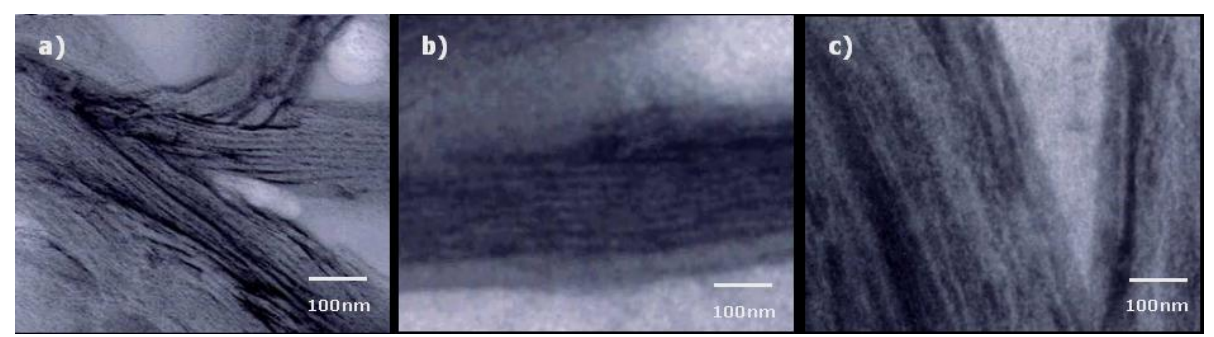

Figure 5. TEM images; a) PE-CTA and purified polymers with PMMA contents of (b) 7.8 wt\% (P-1) and (c) $23 \mathrm{wt} \%(\mathrm{P}-2)$

Figure 6 shows TEM images of sheets of purified polymer with 23 wt $\%$ of PMMA contents and homo-PE/homo-PMMA blend polymer. Those sheets were prepared by the press after anneal at $200{ }^{\circ} \mathrm{C}$.

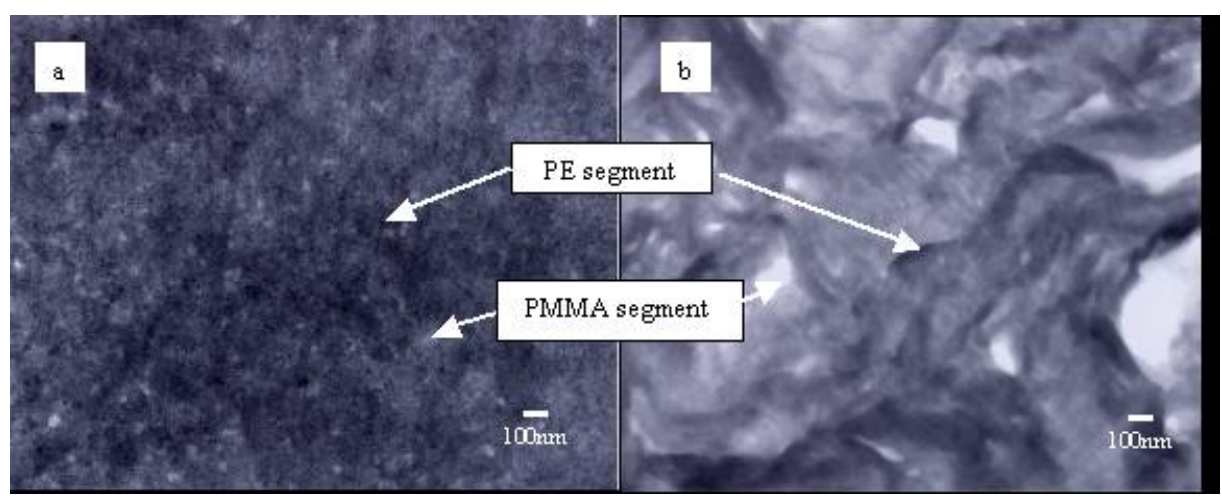

Figure 6. TEM images of polymer sheets; a) purified polymer (PMMA; $23 \mathrm{wt} \%$ ), b) homo-PE / homo-PMMA blended polymer $(\mathrm{PE} / \mathrm{PMMA}=75 / 25 \mathrm{w} / \mathrm{w})$ 
The TEM images of the purified polymer reveal the nanometer level microphaseseparation morphology between the PE segment and PMMA segment different than PE/PMMA blend polymer, similar to PE- $b$-PMMA by ATRP in our previous paper [8]. That would be indicated that polymer hybrid based on PE was synthesized via RAFT polymerization, which is a metal free CRP method.

\section{Conclusion}

PE-PMMA polymer hybrid was synthesized via RAFT polymerization method for the first time using PE-CTA that was prepared by sequential functionalization of terminally hydroxylated PE. The structure of PE-CTA was confirmed by ${ }^{1} \mathrm{H}$ NMR and FT-IR analyses. The results of GPC after MMA polymerization revealed that the molecular weight $\left(M_{\mathrm{w}}\right)$ of the purified polymers increased from 36,600 by PE-CTA, to 38,500 and 40,000, respectively. ${ }^{1} \mathrm{H}$ NMR analysis of purified polymers confirmed that the amounts of PMMA segments were in a range of 7.8 and $23 \mathrm{wt} \%$. TEM micrographs indicated the nanometer level microphase-separation morphology between the PE segment and PMMA segment, suggesting that polymer hybrid based on PE was synthesized via RAFT polymerization method.

\section{References}

1. Kashiwa N, Matsugi T, Kojoh S, Kaneko H, Kawahara N, Matsuo S, Nobori T, Imuta J (2003) J Polym Sci Part A Polym Chem 41:3657

2. Hosoda S, Kihara H, Kojima K, Satoh Y, Doi Y (1991) Polym J 23:277

3. Chung TC (2002) Prog Polym Sci 27:39

4. Shiono T, Akino Y, Soga K (1994) Macromolecules 27:6229

5. Matyjaszewski K, Saget J, Pyun J, Schlogl M, Rieger B (2002) J Macromol Sci Part A Pure Appl Chem 39:901

6. Galli P, Haylock JC, DeNicola A (1995) Macromol Symp 100:95

7. Park ES, Jin HJ, Lee IM, Kim MN, Lee HS, Yoon JS (2002) J Appl Polym Sci 83:1103

8. Matsugi T, Kojoh S, Kawahara N, Matsuo S, Kaneko H, Kashiwa N (2003) J Polym Sci Part A Polym Chem 41:3965

9. Inoue Y, Matyjaszewski K (2004) J Polym Sci Part A Polym Chem 42:496

10. Matsugi T, Kaneko H, Kojoh S, Ono SS, Imuta J, Nobori T, Kawahara N, Matsuo S, Kashiwa N (2003) Proceeding of the 226th ACS National Meeting, New York, U.S.A.

11. Inoue Y, Matsugi T, Kashiwa N, Matyjaszewski K (2004) Macromolecules 37:3651

12. Kaneyoshi H, Inoue Y, Matyjaszewski K (2005) Macromolecules 38:5425

13. Perrier S, Takolpuckdee P, Mars CA (2005) Macromolecules 38:6770

14. Roy D, Guthrie JT, Perrier S (2005) Macromolecules 38:10363

15. Yoshikawa C, Goto A, Tsujii Y, Fukuda T, Yamamoto K, Kishida A (2005) Macromolecules 38:4604

16. Li C, Benicewicz BC (2005) Macromolecules 38:5929

17. Caporaso L, Iudici N, Oliva L (2005) Macromolecules 38:4894

18. Favier A, Charreyre MT (2006) Macromol Rapid Commun 27:653

19. Chiefari J, Chong YK, Ercolo F, Krstina J, Jeffery J, Le TPT, Mayadunne RTA, Meijs GF, Moad CL, Moad G, Rizzardo E, Thang SH (1998) Macromolecules 31:5559

20. Tujii Y, Ejaz M, Sato K, Goto A, Fukuda T (2001) Macromolecules 34:8872

21. Thomas DB, Convertine AJ, Myrick JL, Scales CW, Smith AE, Lowe AB, Vasilieva YA, Ayres N, McCormick CL (2004) Macromolecules 37:8941

22. Imuta J, Kashiwa N, Toda Y (2002) J Am Chem Soc 124:1176 